\title{
Quasi-Sliding Mode Control Based on Reduced Order Mode
}

\author{
Tao Liu* and Hengliang Tang \\ School of Information, Beijing Wuzi University, Beijing, China \\ ${ }^{*}$ Corresponding author
}

\begin{abstract}
A new design method of quasi-sliding mode control is presented for discrete-time system. It is show that the quasisliding mode controller for high order discrete-time system could be changed into the same problem for low discrete-time system utilizing reaching law and reduced model. The numeration complexity for controller design is cut down in large range. At the same time, the stability and dynamic performance could be ensured by new control decision. An example and its simulation results are presented to illustrate the proposed approach.
\end{abstract}

Keywords-discrete-time system; quasi-sliding mode; reduced model; reaching law

\section{INTRODUCTION}

With the rapid development of computer technology, most of the actual control system design is based on discrete-time system. When the sliding-mode control method is used for the discrete-time system, the motion trajectory of the system has quasi-sliding mode and the chattering phenomenon occurs [1][3].

There are some achievements in the study of quasi-slidingmode control for discrete-time systems [4]-[11]. It is generally based on the original high order system. With the increase of the order of the system, the calculation of the system is greatly increased.

We use model reduction method and combine with reaching law method that is proposed to solve the above problems. In this paper, we could see that the quasi-sliding mode control design of high order system is transformed into the design of quasi-sliding mode control strategy for reduced order model. The computational cost of the high order discrete control system is greatly decreased, and satisfactory results are obtained.

\section{SYSTEM DESCRIPTION}

Consider the following discrete-time system

$$
x(k+1)=A x(k)+B u(k)
$$

Where is

$$
x \in R^{n} \quad u \in R^{m}
$$

$A, B$ is with appropriate dimensions. $(A, B)$ is controllable.

By nonsingular transformation

$$
x(k)=\hat{P x}(k)
$$

Discrete-time system (1) can transform into Jordan system

$$
\left[\begin{array}{l}
\hat{x}_{1}(k+1) \\
\hat{x}_{2}(k+1)
\end{array}\right]=\left[\begin{array}{cc}
\Lambda_{1} & 0 \\
0 & \Lambda_{2}
\end{array}\right]\left[\begin{array}{l}
\hat{x}_{1}(k) \\
\hat{x}_{2}(k)
\end{array}\right]+\left[\begin{array}{l}
B_{1} \\
B_{2}
\end{array}\right] u(k)
$$

Where is

$$
\hat{x}_{1} \in R^{r} \hat{x}_{2} \in R^{n-r} m<r<n
$$

$\Lambda_{1}$ and $\Lambda_{2}$ is Jordan block with corresponding dimension. $B_{1}$ and $B_{2}$ is matrix with corresponding dimension.

We assume

(A1). The Jordan block in the system (2) is stable, that is $\rho\left(\Lambda_{2}\right)<1$.

\section{Discrete QuASI-SLIDING Mode CONTROL}

A. Design of Sliding Mode Surface

Consider reduced order system

$$
z(k+1)=\Lambda_{1} z(k)+B_{1} u(k)
$$

Where is

$$
z(k)=C_{a} \hat{x}(k)=\bar{C}_{a} x(k) \quad C_{a}=\left[\begin{array}{ll}
I_{r} & 0
\end{array}\right] \bar{C}_{a}=C_{a} P^{-1}
$$

As in [8], we can design stable sliding surface for reduced order system (3) 


$$
S_{z}(k)=C^{T} z(k)=0 \quad C^{T} \in R^{m \times r}
$$

Theorem1. If the ideal quasi-sliding mode of reduced order system (3) on sliding surface

$$
s_{z}(k)=C^{T} z(k)=0
$$

is asymptotically stable then the ideal quasi-sliding mode of high order system (1) on sliding surface

$$
s(k)=C^{T} \bar{C}_{a} x(k)=0
$$

is asymptotically stable.

Proof. Ideal quasi-sliding mode of reduced order system (3) satisfies

$$
s_{z}(k+1)-s_{z}(k)=C^{T} \Lambda_{1} z(k)+C^{T} B_{1}(k)-C^{T} z(k)=0
$$

Combine system (3) sliding surface (4) and (5), we get equivalent control

$$
u(k)=-\left(C^{T} B_{1}\right)^{-1} C^{T} \Lambda_{1} z(k)
$$

Substitute (6) into system (3) the ideal quasi-sliding mode equation is obtained

$$
z(k+1)=\left[\Lambda_{1}-B_{1}\left(C^{T} B_{1}\right)^{-1} C^{T} \Lambda_{1}\right] z(k)
$$

So if the ideal quasi-sliding mode of reduced order system (3) on sliding surface

$$
s_{z}(k)=C^{T} z(k)=0
$$

is asymptotically stable then

$$
\rho\left(\Lambda_{1}-B_{1}\left(C^{T} B_{1}\right)^{-1} C^{T} \Lambda_{1}\right)<1
$$

$$
\begin{aligned}
\hat{x}(k+1) & =\left[\begin{array}{cc}
\Lambda_{1} & 0 \\
0 & \Lambda_{2}
\end{array}\right] \hat{x}(k)-\left[\begin{array}{l}
B_{1} \\
B_{2}
\end{array}\right]\left(C^{T} B_{1}\right)^{-1} C^{T} \Lambda_{1} z(k) \\
& =\left[\begin{array}{cc}
\Lambda_{1} & 0 \\
0 & \Lambda_{2}
\end{array}\right] \hat{x}(k)-\left[\begin{array}{c}
B_{1} \\
B_{2}
\end{array}\right]\left(C^{T} B_{1}\right)^{-1} C^{T}\left[\begin{array}{ll}
\Lambda_{1} & 0
\end{array}\right] \hat{x}(k) \\
& =\left[\begin{array}{cc}
\Lambda_{1}-B_{1}\left(C^{T} B_{1}\right)^{-1} C^{T} \Lambda_{1} & 0 \\
-B_{2}\left(C^{T} B_{1}\right)^{-1} C^{T} \Lambda_{1} & \Lambda_{2}
\end{array}\right] \hat{x}(k)
\end{aligned}
$$

According to (8) and (A1) the corresponding dynamic for system (2) is asymptotically stable.

So high order system (1) is asymptotically stable with control (6), and do ideal quasi-sliding mode motion on sliding surface

$$
s(k)=C^{T} \bar{C}_{a} x(k)=0
$$

\section{B. Design of Quasi-Sliding Mode Control}

The reduced order model of the system (3) use the reaching law as in [8]

$$
s_{z}(k+1)-s_{z}(k)=-q T s_{z}(k)-\varepsilon T \operatorname{sgn}\left(s_{z}(k)\right)
$$

Combine (3) with (4) the quasi-sliding mode control based on reaching law (10) can be obtained

$$
u(k)=\beta_{1} z(k)+\beta_{2} \operatorname{sgn}\left(C^{T} z(k)\right)
$$

Where is

$$
\beta_{1}=-\left(C^{T} B_{1}\right)^{-1} C^{T}\left(\Lambda_{1}-I+q T\right) \quad \beta_{2}=-\left(C^{T} B_{1}\right)^{-1} \varepsilon T
$$

By

$$
z(k)=\bar{C}_{a} x(k)
$$

(11) can be transformed into

$$
u(k)=\beta_{1} \bar{C}_{a} x(k)+\beta_{2} \operatorname{sgn}\left(C^{T} \bar{C}_{a} x(k)\right)
$$

Theorem2. The control law (13) derived from the low order system is used for high order system (1).It can ensure that the original high order system (1) reaches the sliding surface

$$
s(k)=C^{T} \bar{C}_{a} x(k)=0
$$

in finite time and do quasi-sliding mode motion along the sliding surface. 
Proof. According to system (1), expression (12), control input (13) and sliding mode function (14), we can get

$$
\begin{aligned}
s(k+1)= & C^{T} \bar{C}_{a} x(k+1) \\
= & C^{T} \bar{C}_{a} A x(k)+C^{T} \bar{C}_{a} B u(k) \\
= & C^{T} \bar{C}_{a} A x(k)+C^{T} \bar{C}_{a} B\left(\beta_{1} \bar{C}_{a} x(k)+\right. \\
& \beta_{2} \operatorname{sgn}\left(C^{T} \bar{C}_{a} x(k)\right) \\
= & C^{T} \bar{C}_{a} A x(k)+C^{T} \bar{C}_{a} B \beta_{1} \bar{C}_{a} x(k)+ \\
& C^{T} \bar{C}_{a} \beta_{2} \operatorname{sgn}\left(C^{T} \bar{C}_{a} x(k)\right. \\
= & \left(C^{T} \bar{C}_{a} A+C^{T} \bar{C}_{a} B \beta_{1} \bar{C}_{a}\right) x(k)+ \\
& C^{T} \bar{C}_{a} \beta_{2} \operatorname{sgn}\left(C^{T} \bar{C}_{a} x(k)\right) \\
= & \left(C^{T} C_{a} P^{-1} A-C^{T} C_{a} P^{-1} B\left(C^{T} B_{1}\right)^{-1} C^{T}\left(\Lambda_{1}-I+\right.\right. \\
& \left.q T) \bar{C}_{a}\right) x(k)-C^{T} \bar{C}_{a}\left(C^{T} B_{1}\right)^{-1} \varepsilon T \operatorname{sgn}\left(C^{T} \bar{C}_{a} x(k)\right) \\
= & \left(C^{T} \Lambda_{1}-C^{T}\left(\Lambda_{1}-I+q T\right) \bar{C}_{a}\right) x(k)- \\
& \varepsilon T \operatorname{sgn}\left(C^{T} \bar{C}_{a} x(k)\right) \\
= & (1-q T) C^{T} \bar{C}_{a} x(k)-\varepsilon T \operatorname{sgn}\left(C^{T} \bar{C}_{a} x(k)\right) \\
= & (1-q T) s(k)-\varepsilon T \operatorname{sgn} s(k)
\end{aligned}
$$

Combining the above results (15) we can see high order system (1) has the reaching law similar with reduced order system (3). Further, high order system (1) can reach the sliding surface (14) in finite time and do quasi-sliding mode motion along the sliding surface as in [8].

\section{NUMERICAL SIMULATION}

Consider the following three order discrete-time system (high order system)

$$
x(k+1)=\left[\begin{array}{ccc}
4.2072 & -2.7579 & 0.2014 \\
6.4598 & -4.5658 & 0.4120 \\
19.3694 & -16.6863 & 2.2339
\end{array}\right] x(k)+\left[\begin{array}{c}
-0.3431 \\
-0.5546 \\
-1.6633
\end{array}\right] u(k)(16)
$$

Where is

$$
x(0)=\left[\begin{array}{lll}
0.5 & 0.5 & 0.5
\end{array}\right]
$$

By nonsingular transformation for system (16)

$$
x(k)=\hat{P x}(k)
$$

Where is

$$
P=\left[\begin{array}{lll}
3 & 2 & 1 \\
4 & 3 & 2 \\
7 & 9 & 6
\end{array}\right]
$$

System (16) become

$$
\hat{x}(k+1)=\left[\begin{array}{ccc}
1 & 0.001 & 0 \\
0 & 0.9753 & 0 \\
0 & 0 & -0.1
\end{array}\right] \hat{x}(k)+\left[\begin{array}{c}
-0.0001 \\
-0.1314 \\
-0.08
\end{array}\right] u(k)
$$

The reduced order system of system (17) is

$$
z(k+1)=\left[\begin{array}{cc}
1 & 0.001 \\
0 & 0.9753
\end{array}\right] z(k)+\left[\begin{array}{c}
-0.0001 \\
-0.1314
\end{array}\right] u(k)
$$

The switching surface of the reduced order model system (18) is obtained

$$
S_{z}(k)=C^{T} Z(k)=\left[\begin{array}{ll}
5 & 1
\end{array}\right] z(k)
$$

In reaching law (10)

$$
T=1 m s \quad q=20 \varepsilon=0.3
$$

The control law of the reduced order model system (18) based on (11) is

$$
u(k)=\left[\begin{array}{ll}
0.5686 & -0.0356
\end{array}\right] \mathrm{z}(\mathrm{k})+0.0228 \operatorname{sgn}\left(\left[\begin{array}{ll}
5 & 1
\end{array}\right] \mathrm{z}(\mathrm{k})\right)
$$

Accordingly the control law of high order system (16) can be obtained

$$
\begin{aligned}
u(k)= & {\left[\begin{array}{llll}
-0.0712 & 0.4195 & -0.1280
\end{array}\right] \mathrm{x}(\mathrm{k})+} \\
& 0.0228 \operatorname{sgn}\left(\left[\begin{array}{lll}
2.0000 & 0.8000 & -0.6000
\end{array}\right] \mathrm{x}(\mathrm{k})\right)
\end{aligned}
$$

Figure 1- Figure 3 shows the system, the control input and the state and sliding mode function of the high order system. 


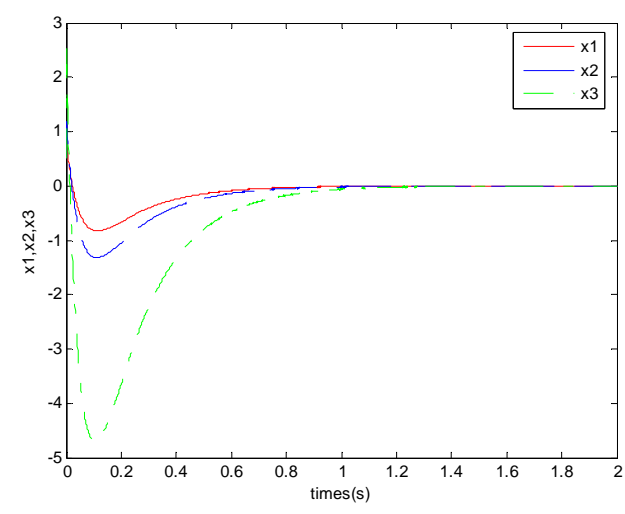

FIGURE I. SYSTEM STATE

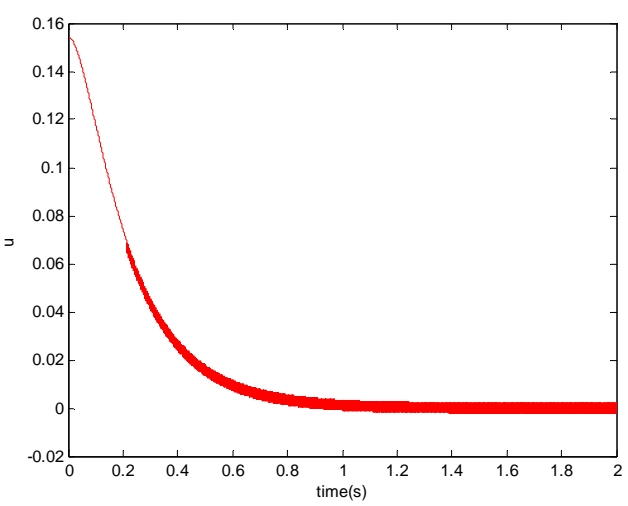

FIGURE II. CONTROL INPUT

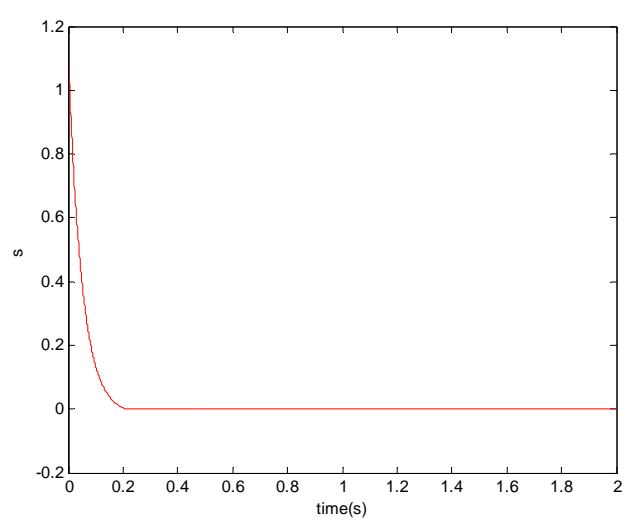

FIGURE III. SLIDING MODE FUNCTION

\section{CONCLUSION}

We propose a new design method of quasi-sliding mode control is presented for discrete-time system. The high order discrete-time system is transformed into Jordan standard system by nonsingular transformation. According to the Jordan standard system to obtain the corresponding reduced order system. The control law that is on the basis of reaching law design method for reduced system is applied directly to the high order system. The stability and dynamic performance of the system are analyzed. The simulation results show that the discrete-time system control based on reduced order model can make the state of the system converge quickly to the origin.

\section{ACKNOWLEDGMENT}

This paper is supported by Funding Project for Beijing Key Laboratory of Intelligent Logistics System and Beijing Intelligent Logistics System Collaborative Innovation Center, Beijing Outstanding Talent Fund Key Individual Project (No.2014000020124G091), Beijing Wuzi University Highlevel Project Cultivate Fund (No. GJB20143005), Beijing Social Science Fund Youth Project (No.16GLC064), General Program of Science and Technology Development Project of Beijing Municipal Education Commission of China (No. KM201610037001, No. KM201710037001), Open Project of State Key Laboratory of Virtual Reality Technology and System of China (No.BUAA-VR-16KF-21).

\section{REFERENCES}

[1] L. T. Ren, S. S. Xie, Y. Zhang, J. B. Peng, L. D. Zhang, "Chattering analysis for discrete sliding mode control of distributed control systems," Journal of Systems Engineering and Electronics,vol. 27, pp.1096-1107, October 2016.

[2] A. Bartoszewicz, "Discrete-time quasi-sliding-mode control strategies," IEEE Trans. on Industrial Electronics, vol. 45, pp. 633-637, April 1998.

[3] J. L. Chang, "Discrete sliding-mode control of mimo linear systems," Asian Journal of Control, vol. 4, pp. 217-222, June 2002.

[4] A. Jafari Koshkouei, A. S. I. Zinober, "Sliding mode control of discretetime systems,” Journal of Dynamic Systems Measurement and Control, vol. 122, pp. 793-802, December 2000.

[5] T. Liu, H. P. Liu, W. Qu, “ Quasi-sliding-mode control based on timevariant reaching law,” Control and Decision, vol. 25, pp. 797-800, May 2010.

[6] T. Liu, H. P. Liu, "Quasi-sliding-mode control based on discrete reaching law with dead zone,” Acta Automatica Sinica, vol. 37, pp. 760766, June 2011.

[7] D. W. Zhou, C. C. Gao, Z. Q. Li, "Reaching law of discrete-time variable structure control system," Control and Decision, vol 23, pp. 306-309, March 2008.

[8] W. B. Gao, G. F. Wang, A. Homaifa, "Discrete-time variable structure control systems,” IEEE Trans. on Industrial Electronics, vol 42, pp. 117122, April 1995.

[9] X. H. Yu, S. H. Yu, "Discrete sliding mode control design with invariant sliding sectors,” Journal of Dynamic Systems Measurement and Control, vol 122, pp.776-782, December 2000.

[10] J. H. Zhang, X. W. Liu, Y. Q. Xia, Z. Q. Zuo, Y. J. Wang, “Disturbance observer-based integral sliding-mode control for systems with mismatched disturbances,” IEEE Trans. on Industrial Electronics, vol 63, pp. 7040-7048, November 2016.

[11] K. Peng, B. Chen, G. Cheng, T. Lee, "Modeling and compensation of nonlinearities and friction in a micro hard disk servo system with nonlinear feedback control," IEEE Trans. on Control Systems Technology, vol. 13, pp. 708-721, May 2005. 